\title{
Different pontic design for porcelain fused to metal fixed dental prosthesis: Contemporary guidelines and practice by general dental practitioners
}

\author{
Syed Murtaza Raza Kazmi ${ }^{1}$, Zahid Iqbal ${ }^{2}$, Muhammad Usman Muneer ${ }^{3}$, Samiya Riaz ${ }^{4}$, \\ Muhammad Sohail Zafar ${ }^{5,6}$
}

Correspondence: Dr. Muhammad Sohail Zafar

Email: drsohail_78@hotmail.com

\begin{abstract}
'Department of Prosthodontics, Fatima Jinnah Dental College, Karachi, Pakistan,

${ }^{2}$ Department of Prosthodontics, Fatima Memorial Hospital College of Dentistry, Lahore, Pakistan, ${ }^{3}$ Department of Prosthodontics, Lahore Medical and Dental College, Lahore, Pakistan,

${ }^{4}$ Department of Paediatric Dentistry, School of Dental Sciences, Universiti Sains Malaysia, Kelantan, Malaysia,

${ }^{5}$ Department of Restorative Dentistry, College of Dentistry, Taibah University, Madinah, Munawwarah, Saudi Arabia,

${ }^{6}$ Department of Dental Materials, Islamic International Dental College, Riphah International University, Islamabad, Pakistan
\end{abstract}

\section{ABSTRACT}

Objective: The current study aimed to assess the knowledge and practice of pontic design selection by the general dental practitioners (GDPs) in the light of contemporary guidelines. Materials and Methods: This cross-sectional study was conducted among the GDPs of Karachi. A questionnaire was designed to collect data from 100 GDPs. The questionnaire included general/demographic information (practitioner's education, experience, and place of practice) and an average number of fixed prosthesis constructed by the GDP. The questionnaire was further categorized to evaluate the knowledge/practice of pontic design selection and latest recommendations. Results: For the maxillary anterior segment, the ridge lap pontic was the most common (32\%) followed by the modified ridge lap (28\%). In the maxillary posterior segment, the ridge lap pontic was the most common (37\%) followed by sanitary design (34\%). For the mandibular anterior segment, the modified ridge lap (50\%) was the most common followed by ridge lap pontic (17\%). In case of the mandibular posterior segment, the sanitary design (34\%) was the most common followed by ridge lap pontic (30\%). Conclusions: The pontic design selection for the fixed prosthesis is a neglected domain. The contemporary guidelines are not followed with full spirit by the GDPs leading to wide variations in the pontic design selection.

Key words: Fixed prosthesis, pontics, porcelain fused to metal bridges

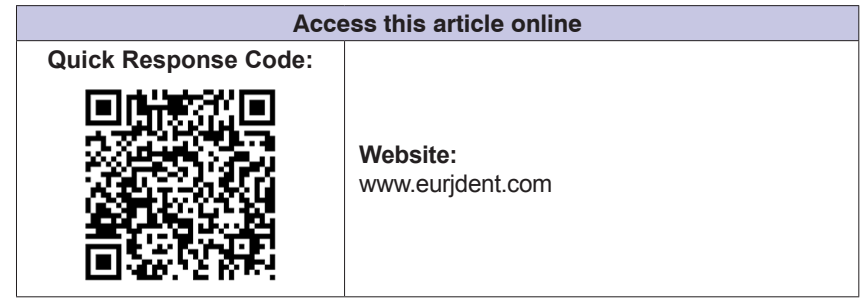

This is an open access journal, and articles are distributed under the terms of the Creative Commons Attribution-NonCommercial-ShareAlike 4.0 License, which allows others to remix, tweak, and build upon the work non-commercially, as long as appropriate credit is given and the new creations are licensed under the identical terms.

For reprints contact: reprints@medknow.com

How to cite this article: Raza Kazmi SM, Iqbal Z, Muneer MU, Riaz S, Zafar MS. Different pontic design for porcelain fused to metal fixed dental prosthesis: Contemporary guidelines and practice by general dental practitioners. Eur J Dent 2018;12:375-9.

DOI: 10.4103/ejd.ejd_232_18 


\section{INTRODUCTION}

Pontic is the artificial tooth in the fixed or removable partial dentures; that is, the suspended portion of the fixed partial denture (bridge) replacing the missing natural tooth or teeth. ${ }^{[1]}$ The pontic may be fabricated from cast metal or combination of metal and porcelain. ${ }^{[2]}$ Designing a pontic is not simple; an exact anatomic replica of the tooth in the space would be difficult to manage. ${ }^{[3]}$ The requirements of the pontic design include esthetics, biocompatibility, function, phonetics, patient comfort, and maintenance of healthy tissue on the edentulous ridge. ${ }^{[4-7]}$ Pontic design selection depends on the location of the edentulous area. Controversies exist for the gingival embrasure space and design. Some considered less plaque accumulation with space closure while other proposed open embrasure space for oral hygiene maintenance pontic. ${ }^{[8,9]}$

Pontic resembles the tooth morphology and may be altered to meet extra demands in certain clinical scenarios such as in case of convex tissue surfaces and narrow occlusal table. ${ }^{[9]}$ Decreasing the buccolingual width lead to decrease in interferences in eccentric movements. ${ }^{[7]}$ Some authors considered normal size occlusal table, whereas other considered it to be of minimum importance ${ }^{[7-9]}$ Pontic should be out of tissue contact when proceeding from facial to lingual. ${ }^{[10]}$

Different shapes of pontic are selected according to the position of the edentulous space, amount of bone resorption, and operator's and patient's preferences. ${ }^{[11]}$ It is recommended that the prosthodontist or the dental practitioner should advise the dental laboratory about the shape of the desired pontic for the fixed prosthesis. ${ }^{[12]}$ There is a variety of pontic designs (such as ridge lap, ovate, and conical) for mandibular and maxillary arches [Figure 1].

For instance, ovate and modified ridge lap is recommended for the anterior maxilla, sanitary and modified ridge lap for the posterior maxilla, conical, and modified ridge lap for the anterior mandible and sanitary for the posterior mandible, respectively. $[9,11,13,14]$ These guidelines should be followed to provide the patient with an acceptable prosthesis. This survey-based study was undertaken to assess the knowledge and practice of pontic selection by the general dental practitioners (GDPs) in the light of contemporary guidelines. Porcelain fused to metal fixed prostheses were included as these are most commonly used prosthesis by GDPs.

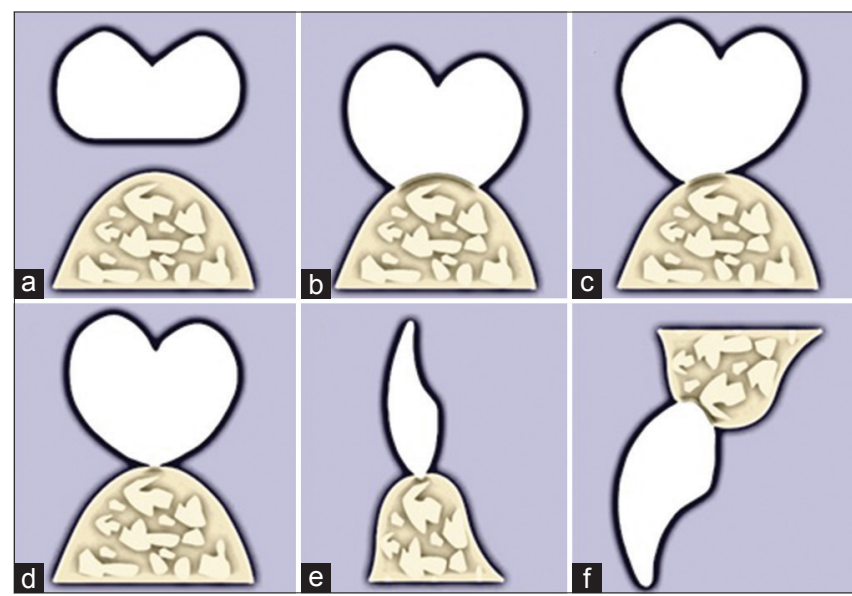

Figure 1: Schematic presentation of various pontic designs; (a) Sanitary pontic; has no contact with the edentulous ridge, (b) ridge lap pontic; forms a large concave contact replacing the contours of a missing tooth, (c) modified ridge lap; shows illusion of a tooth but it has all or nearly all convex surfaces for easy cleaning and minimize plaque accumulation, ( $\mathrm{d}$ and e) bullet/conical; rounded and cleanable smaller tip in relation to overall size, (f) ovate; round end design currently in use where aesthetics is a primary concern

\section{MATERIALS AND METHODS}

This cross-sectional study was conducted among the GDPs of Karachi, Pakistan. The study protocol was approved by the Institutional Ethics Review Board at the Fatima Jinnah Dental College, Karachi. The data were collected using a comprehensive questionnaire over a period of 6 months (January-June 2017). A total of 100 GDPs of Karachi were included in the study. A self-administered questionnaire with multiple choices was designed. Before its distribution, it was discussed thoroughly to ensure that the questions were clear. Any question with ambiguity was modified and rephrased. The questionnaire included general/demographic information related to the practitioner's education, experience and place of practice and an average number of a fixed prosthesis constructed by the GDP per month. The questionnaire was further categorized to evaluate the GDPs' knowledge/preference about the pontic design selection and latest recommendations. The questionnaire included various pontic designs [Figure 1] and their selection preferences according to the quadrants were enquired. Multiple options were given, and the participant had to mark maximum two options for every question. One of the key questions was, "did the practitioner advises the dental laboratory about the type of pontic?". One of the authors himself approached the practitioners to get the questionnaire filled. After getting the consent to take part in the study the participants were given a clear and detailed briefing about the aims 
and objectives of the study. It was assured that the results obtained will be used for the study purposes only and the information will be confidential. The questionnaires were filled by the qualified dental practitioner only. Responses from the participants were evaluated in terms of numbers and percentages using the SPSS Version 20 (IBM, Illinois, USA). The statistical test (Chi-square) was applied to compare the statistical significance among groups, whereas $P<0.05$ was considered as statistically significant.

\section{RESULTS}

Out of total 100 invited practitioners, 70 (70\%) participants (53 males and 17 females) agreed to participate and completed the questionnaire. Another ten questionnaires either incomplete or not returned by the participants were excluded. Therefore, 60 questionnaires were considered appropriate and included in the study. Only 18 (30\%) participants reported to advise the dental laboratory about the type of pontic design while remaining $42(70 \%)$ used to give no instructions to the dental laboratory and to accept the pontic design provided by their dental laboratory.

The participants' preference for choosing the pontic design for maxillary and mandibular segments is shown in Table 1. For the maxillary anterior segment, the ridge lap pontic was the most common (32\%) followed by the modified ridge lap $(28 \%)$ and ovate $(15 \%)$. In case of the maxillary posterior segment, the ridge lap pontic was the most common (37\%) followed by sanitary design (34\%) and modified ridge lap $(10 \%)$. The conical design pontic remains the least common design for all kinds of maxillary restorations [Table 1].

For the mandibular anterior segment, the modified ridge lap (50\%) was the most common followed by ridge lap pontic $(17 \%)$ and conical (13\%). In case of the mandibular posterior segment, the sanitary design (34\%) was the most common followed by ridge lap pontic $(30 \%)$ and modified ridge lap $(17 \%)$. The sanitary design pontic remains the least chosen (3\%) for the mandibular anterior segment and ovate $(0 \%)$ for mandibular posterior restorations [Table 1]. The collective data showed that the most popular pontic design among participant is the ridge lap pontic $(69 \%)$ followed by modified ridge lap (63\%) and sanitary (47\%) pontic [Table 2]. Whereas, the ovate and conical were the least popular pontic designs.

\section{DISCUSSION}

This study investigated whether the practicing dentist follows the contemporary guidelines while selecting a metal-ceramic pontic for fixed partial dentures. It is desired to match the physical and mechanical properties of casting alloy and ceramic. For instance, the gross mismatch in the thermal expansion properties of veneering ceramics and metallic core may induce residual stresses, crack formation and potentially chipping failure. ${ }^{[15]}$ To avoid metal-ceramic interface failure due to residual stresses, an appropriate thickness of the veneering porcelain is recommended. ${ }^{[16]}$ The majority of the participants were males corresponding to the higher ratio of practicing male dentists. ${ }^{[17,18]}$ The majority of participants did not give instructions to the dental laboratory about the pontic design. This result is very alarming in the sense that to prescribe the pontic design to the dental laboratory is a fact and it's the job and responsibility of the practitioner to advise and discuss the suitable pontic design with the laboratory technician. ${ }^{[12]}$ Recommended guidelines for the laboratory prescription have mentioned pontic design as an integral part of the prescription. ${ }^{[19,20]}$

The recommended designs for the anterior maxillary region are ovate and modified ridge lap pontics.

\begin{tabular}{|c|c|c|c|c|}
\hline \multirow[t]{2}{*}{ Pontic design } & \multicolumn{2}{|r|}{ Maxillary } & \multicolumn{2}{|c|}{ Mandibular } \\
\hline & Anterior (\%) & Posterior (\%) & Anterior (\%) & Posterior (\%) \\
\hline Ridge lap & $19(32)$ & $22(37)$ & $10(17)$ & $18(30)$ \\
\hline Modified ridge lap & $17(28)$ & $6(10)$ & $30(50)$ & $10(17)$ \\
\hline Ovate & $9(15)$ & $2(3)$ & $6(10)$ & 0 \\
\hline Conical & 0 & $2(3)$ & $8(13)$ & $7(12)$ \\
\hline Sanitary & $2(3)$ & $20(34)$ & $2(3)$ & $23(38)$ \\
\hline Don't know & $13(22)$ & $8(13)$ & $4(7)$ & $2(3)$ \\
\hline Recommendation & $\begin{array}{l}\text { Ovate and modified } \\
\text { ridge lap }\end{array}$ & $\begin{array}{l}\text { Modified ridge lap (premolars) and sanitary } \\
\text { (molars) }\end{array}$ & $\begin{array}{l}\text { Conical and modified } \\
\text { ridge lap }\end{array}$ & $\begin{array}{l}\text { Sanitary and } \\
\text { conical }\end{array}$ \\
\hline
\end{tabular}




\begin{tabular}{lc}
$\begin{array}{l}\text { Table 2: Overall general dental practitioners' } \\
\text { preference of pontic design selection }(\boldsymbol{n = 6 0 )}\end{array}$ \\
\hline Pontic design & Preference (\%) \\
\hline Ridge lap & 69 \\
Modified ridge lap & 63 \\
Sanitary & 47 \\
Don't know & 27 \\
Ovate & 17 \\
Conical & 17 \\
\hline
\end{tabular}

The ovate pontic has high aesthetic value, therefore, considered most suitable in the anterior maxillary region. ${ }^{[14]}$ This gives the illusion that the replaced tooth emerges from the gingiva like a natural tooth. Certain guidelines need to be followed when considering the provision of ovate pontic such as atraumatic extraction, long-term provisional restoration and repeated relining/modification of the provisional restoration. ${ }^{[21]}$ The modified ridge lap is the second commonly recommended pontic design. However, due to alveolar bone resorption changes need to be made in its design which can compromise esthetic and function. ${ }^{[9]}$ Hirshberg considered that oral mucosa remain healthy under the modified ridge lap. ${ }^{[8]}$ This study revealed that $\sim 57 \%$ of the GDPs are not following the contemporary guidelines and relying on designs that may compromise esthetics in this highly esthetic zone.

The recommended designs in the posterior maxillary region are modified ridge lap and sanitary pontics. The maxillary premolar areas are visible when viewed from the front, especially when the patient has a wide smile curvature. Modified ridge lap is the highly recommended design in the maxillary premolar region. ${ }^{[9]}$ Maxillary molars are less visible having no esthetic value. Sanitary/hygienic pontic is frequently used in the nonappearance zone. In sanitary type, the metallic pontic has at least $3 \mathrm{~mm}$ space between the ridge and the pontic to facilitate proper cleaning. ${ }^{[22]}$ Again, $~ 56 \%$ were not following the guidelines for the pontic selection; as $\sim 37 \%$ used ridge lap pontic that is highly unhygienic and may damage the ridge tissues.

The recommended designs in the mandibular anterior region are conical and modified ridge lap pontics. Mandibular anterior teeth are partially visible and only the occlusal/incisal two-thirds of the teeth can be seen in most of the patients. The gingival or cervical third is visible in very few patients having very thin lips or extremely wide smile. ${ }^{[23]}$ However, this area has some role in phonetics. ${ }^{[2]}$ Therefore, to provide phonetics and esthetics to the patients, pontic can slightly touch the ridges, but in cases of severe resorption, pontic can be away. A conical, bullet, or spheroid pontic is recommended in this region. ${ }^{[13,24]}$ The modified ridge lap pontic is also recommended in this region to complete the less esthetic demands. ${ }^{[9]}$ The results of the study showed that the practitioners are less aware of the conical pontic and only $13 \%$ used this type of pontic. Majority of participants (50\%) used modified ridge lap pontic for the anterior mandibular region.

The recommended designs for the mandibular posterior region are sanitary, modified ridge lap pontic and conical pontics. The mandibular posterior teeth have least esthetic values, and only the occlusal surface is visible in phonetics and smiling. Therefore, pontics in this region may ideally be out of gingival/tissue contact to provide good hygiene and cleansibilty. ${ }^{[22]} \mathrm{A}$ narrow occlusal table and convex surface for easy cleaning can be used. ${ }^{[9]}$ Thus, the sanitary and modified sanitary pontic designs are considered ideal for this region. Hood et al..$^{[6]}$ found that sanitary designs bear higher load compared to ridge lap and modified ridge lap pontics. A sanitary design meets the patient's structural, functional, biological and psychological demands. ${ }^{[22]}$ Unfortunately, a few dentists do not prefer sanitary pontic design due to an unnatural sensation of the restoration to the cheek and tongue. ${ }^{[22,25]}$ For such cases, conical and modified ridge, lap pontics can be provided. These guideline were followed by $67 \%$ of participants.

A considerable number of participants preferred saddle type of pontic; these findings are in agreement with Nagarsekar et al. ${ }^{[12]}$ The ridge lap pontic was preferred design in all areas of the mouth and no consideration was given to the specific area. Modified ridge lap pontic was the second commonly used pontic design in this study. Saddle-shaped/ridge lap pontic has high esthetic value and least chances of food particles trapping. This design gives the illusion of a nonextracted tooth which is accepted by the patient. ${ }^{[26]}$ However, this design is the most difficult to clean, because there will be food accumulation between the tissue surface of the pontic and the alveolar ridge surface which will lead to tissue inflammation and failure of restoration. The contemporary guidelines are against the use of this pontic design. ${ }^{[9,27,28]}$ The reasons for variability in the pontic selection should be studied further. This study had a small sample size, and in future, a large sample size can be selected and GDPs of other cities can be included in the study. Particular attention should be given in case of complications 
in the pontic area in relation to abutment crowns such as malalignment, narrow edentulous space, and excessive bone resorption.

\section{CONCLUSIONS}

The current study concluded that the pontic design selection is a neglected domain in fixed partial denture provision. The contemporary guidelines are not followed with full spirit by the GDP participants hence reported a large variability in pontic design selection. Further studies on this topic are recommended to know the reasons for this disparity.

\section{Financial support and sponsorship}

Nil.

\section{Conflicts of interest}

There are no conflicts of interest.

\section{REFERENCES}

1. Shillingburg HT, Sather DA, Wilson EL, Cain J, Mitchell D, Blanco L, et al. Fundamentals of Fixed Prosthodontics. Surrey, United Kingdom: Quintessence Publishing Company; 2012.

2. Cavazos E Jr. Tissue response to fixed partial denture pontics. J Prosthet Dent 1968;20:143-53.

3. Parkinson CF, Schaberg TV. Pontic design of posterior fixed partial prostheses: Is it a microbial misadventure? J Prosthet Dent 1984;51:51-4.

4. Behrend DA. The design of multiple pontics. J Prosthet Dent 1981;46:634-8.

5. Howard WW, Ueno H, Pruitt CO. Standards of pontic design. J Prosthet Dent 1982;47:493-5.

6. Hood JA, Farah JW, Craig RG. Stress and deflection of three different pontic designs. J Prosthet Dent 1975;33:54-9.

7. Johnston JF, Phillips RW, Dykema RW. Modern Practice in Crown and Bridge Prosthodontics. Philadelphia, USA: W.B. Saunders Company; 1971.

8. Hirshberg SM. The relationship of oral hygiene to embrasure and pontic design - A preliminary study. J Prosthet Dent 1972;27:26-38.
9. Rosenstiel SF, Land MF, Fujimoto J. Contemporary Fixed Prosthodontics-E-Book. Sr. Louis, Missouri, USA: Elsevier Health Sciences; 2015.

10. Tripodakis A, Konstantinidis A. Tissue response under hyperpressure from convex pontics. Hell Stomatol Chron 1989;33:159-64.

11. Singh S, Singh N. Treatment planning for fixed partial dentures. Int J Oral Health Med Sci 2015;2:99-101.

12. Nagarsekar A, Gaunkar R, Aras M. Knowledge, attitude, and practice of dental professionals regarding the effect and management of food impaction associated with fixed partial denture prostheses: A survey. J Indian Prosthodont Soc 2016;16:372-9.

13. Kang HS, Lee SY. Immediate fixed partial denture after tooth extraction in patients with systemic diseases: A clinical report. J Adv Prosthodont 2016;8:511-4.

14. Supamitsatian T, Leevailoj C. Restoration of maxillary anterior bridges with ovate pontics design: A case report. Mahidol Dent J 2014;34:70-81

15. Mainjot AK, Schajer GS, Vanheusden AJ, Sadoun MJ. Residual stress measurement in veneering ceramic by hole-drilling. Dent Mater 2011;27:439-44

16. Löfgren N, Larsson C, Mattheos N, Janda M. Influence of misfit on the occurrence of veneering porcelain fractures (chipping) in implant-supported metal-ceramic fixed dental prostheses: An in vitro pilot trial. Clin Oral Implants Res 2017;28:1381-7.

17. Tahir S, Bashir A, Rafique A, Khan J. Factors that support female dentists in pursuing their profession in Pakistan. Biomedica 2017;33:107-12

18. Tahir S, Bashir A, Khan J. Factors that hinder female dentists in pursuing their career. Biomedica 2014;30:1-6.

19. Berry J, Nesbit M, Saberi S, Petridis H. Communication methods and production techniques in fixed prosthesis fabrication: A UK based survey. Part 1: Communication methods. Br Dent J 2014;217:E12.

20. Lynch CD, Allen PF. Quality of communication between dental practitioners and dental technicians for fixed prosthodontics in Ireland. J Oral Rehabil 2005;32:901-5.

21. Zitzmann NU, Marinello CP, Berglundh T. The ovate pontic design: A histologic observation in humans. J Prosthet Dent 2002;88:375-80.

22. Tjan AH. A sanitary "arc-fixed partial denture": Concept and technique of pontic design. J Prosthet Dent 1983;50:338-41.

23. Edelhoff D, Spiekermann H, Yildirim M. A review of esthetic pontic design options. Quintessence Int 2002;33:736-46.

24. Porter CB Jr. Anterior pontic design: A logical progression. J Prosthet Dent 1984;51:774-6.

25. Kim TH, Cascione D, Knezevic A. Simulated tissue using a unique pontic design: A clinical report. J Prosthet Dent 2009;102:205-10.

26. Gade E. Hygienic problems of fixed restorations. Int Dent J 1963;13:318.

27. Ganani RP, Mistry G, Shetty O. The phoenix pontic: A review article. Health Talk 2012;4:45-7.

28. Spear FM. Maintenance of the interdental papilla following anterior tooth removal. Pract Periodontics Aesthet Dent 1999;11:21-8. 